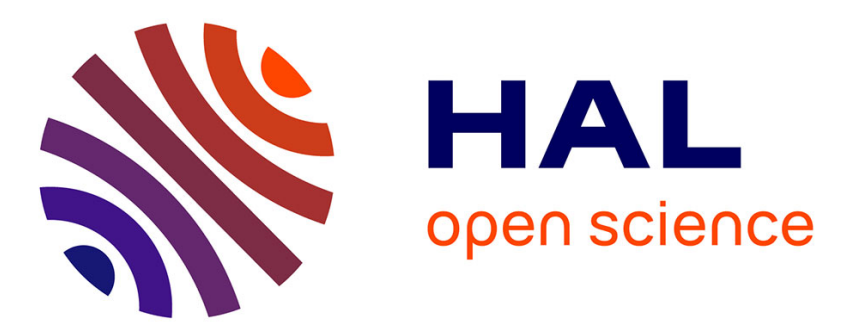

\title{
Electrical investigation of a pin-to-plane dielectric barrier discharge in contact with water
}

Tian Tian, Hervé Rabat, Monica Magureanu, Olivier Aubry, Dunpin Hong

\section{To cite this version:}

Tian Tian, Hervé Rabat, Monica Magureanu, Olivier Aubry, Dunpin Hong. Electrical investigation of a pin-to-plane dielectric barrier discharge in contact with water. Journal of Applied Physics, 2021, 130 (11), pp.113301. 10.1063/5.0056654 . hal-03347061

\section{HAL Id: hal-03347061 \\ https://hal.science/hal-03347061}

Submitted on 16 Sep 2021

HAL is a multi-disciplinary open access archive for the deposit and dissemination of scientific research documents, whether they are published or not. The documents may come from teaching and research institutions in France or abroad, or from public or private research centers.
L'archive ouverte pluridisciplinaire HAL, est destinée au dépôt et à la diffusion de documents scientifiques de niveau recherche, publiés ou non, émanant des établissements d'enseignement et de recherche français ou étrangers, des laboratoires publics ou privés. 


\title{
Electrical investigation of a pin-to-plane Dielectric Barrier Discharge in contact with water
}

\author{
Tian Tian ${ }^{1, *}$, Hervé Rabat ${ }^{1}$, Monica Magureanu ${ }^{2}$, Olivier Aubry ${ }^{1}$ and Dunpin Hong ${ }^{1, *}$ \\ ${ }^{1}$ GREMI, CNRS Université d'Orléans, BP6744, 14 rue d'Issoudun, 45067 Orléans Cedex 2, \\ France
}

${ }^{2}$ Department for Plasma Physics and Nuclear Fusion, National Institute for Lasers, Plasma and Radiation Physics, Atomistilor Street 409, Magurele, Ilfov 077125, Romania

* Corresponding authors: tian.tian@univ-orleans.fr and dunpin.hong@univ-orleans.fr

\begin{abstract}
Numerous investigations on plasma-liquid interaction have been published in the literature using various reactor geometries. However, our understanding of the basic configuration of a pin-to-plane dielectric barrier discharge (DBD) in contact with water is still incomplete. We therefore performed the electrical diagnostics of such a discharge, operated in a.c. regime with sinusoidal high voltage, focusing mainly on the power injected into the plasma in relation with several experimental parameters. It was found that the injected power increased linearly with the amplitude of the applied voltage, while without water the evolution followed a second-order polynomial. In both cases, the discharge power was proportional approximately with the frequency. For the DBD above water, the power was about three times greater than that without water, for the same air gap. It was observed that changing the discharge gap from 1 to $5 \mathrm{~mm}$ led to a slight increase in power, by only $15 \%$. The water conductivity also influenced the power injected into the plasma only to a small extent. Thus, the variation in water conductivity over four orders of magnitude determined a fluctuation in discharge power of $\pm 20 \%$.
\end{abstract}

\section{INTRODUCTION}

Because of their potentially important applications, especially in environmental fields, nonthermal plasmas in and in contact with liquids have recently been extensively studied $[1,2]$. The first publication cited here conducted a fairly comprehensive review of work in this 
challenging domain and provided a roadmap. The authors listed six electrical-mechanical configurations typically used to study discharge-liquid interaction, among which the pin-towater plane configuration with liquid as a grounded electrode (and with optionally a gas flow from the pin to the liquid, to provide a linear jet as in the configuration (C) in FIG. 2 of the cited paper), which was finely investigated by Bruggeman and colleagues, and reported in several interesting papers. For instance, in a short paper published in 2008 [3], electrical breakdown in a metal-to-water electrode system with DC applied voltages without overvoltage was studied for inter-electrode distances ranging from 2 to $12 \mathrm{~mm}$. In comparison to most of the other setups listed by several review papers and book chapters concerning plasma-liquid interaction $[1,2$, 4-6], this configuration is easy to implement in order to produce corona discharges above liquid, which are commonly used in work concerning the plasma degradation of antibiotics or other pollutants [7-11]. However, this configuration has a major drawback, namely a possible discharge transition from the streamer regime to the spark regime with a strong discharge current, and hence a strong dissipated energy that could damage the device. Adding a dielectric to the device in order to limit the current is a commonly used technique and the discharge then becomes a discharge called Dielectric Barrier Discharge (DBD) in which the current is selflimited [12, 13]. Some authors used such a pin-to-water DBD configuration to degrade pharmaceutical molecules in water with a non-thermal plasma [14, 15], while Marotta et al [16] used a wire-to-water DBD configuration to degrade aqueous phenol. In both cases, the electrodes are not in contact with the liquid, thus preventing the introduction of metal ions from electrolysis at the submerged electrode into the treated solution. Surprisingly, there are no detailed studies of the discharge created in this DBD over water configuration, whereas there are many studies on a similar configuration without water $[17,18]$. To fill this gap, we performed a study on this basic configuration. Note that our discharge configuration, consisting of a high voltage pin electrode to water separated from the grounded electrode by a dielectric, similar to the ones investigated by Vanraes et al [19] and Li et al [20]. Actually, in reference [19], the high voltage pin electrode was enclosed in a quartz tube and the grounded electrode was covered by a thin layer of water; in reference [20], the plasma was generated between a high voltage pin electrode and a $1.5 \mathrm{~mm}$ thick quartz glass that covered the grounded water electrode. The work reported here focused on the electrical investigation of a pin-to-plane DBD discharge with the presence of water above the dielectric. Specifically, it dealt with the influence of several experimental parameters on the dissipated power. The voltage, the 
discharge current and the current integration were measured, as well as the light emitted by the discharge thanks to a photomultiplier tube (PMT). The adjusted operational parameters included conductivity $\sigma$ and the distance between the electrode and the surface of the water $d$. Indeed, when using non-thermal plasma to treat polluted water, the conductivity of the water can vary greatly from sample to sample, hence it is important to study the influence of conductivity on injected power. In a real application, it is not easy to maintain a constant distance between the electrode and the surface of the water, so it is also important to investigate the influence of distance on injected power.

The next section will present the experimental setup and operating conditions, and the discharge behaviors. The third section will deal with the results and discussion, followed by a short summary.

\section{EXPERIMENTAL SETUP AND DISCHARGE BEHAVIOR}

FIG. 1 (a) is a scheme of the experimental setup including the electrical discharge device. The applied high voltage (HV) was provided by a voltage amplifier (TREK 30/20 A) driven by a function generator (Aim TTi ${ }^{\circledR}$ TGA4001). A capacitor $C_{m}$ with a value of $2.15 \mathrm{nF}$ was placed in series with the discharge device to measure the charge conveyed in the circuit, which was the integration of the discharge current, in order to determine the power dissipated by the discharge thanks to the method known as a $Q$ - $V$ diagram or Lissajous figure. The voltage at the terminals of this capacitor was measured with a probe with an input impedance of $100 \mathrm{M} \Omega$ (Tektronix ${ }^{\circledR}$ P6015A, $75 \mathrm{MHz}$ bandwidth), while the applied voltage was measured with a HV probe (Lecroy ${ }^{\circledR}$ PPE $20 \mathrm{kV}, 100 \mathrm{MHz}$ bandwidth). The current in the circuit was monitored by a current transformer (CT-C5.0 from Magnelab ${ }^{\circledR}, 4800 \mathrm{~Hz}-400 \mathrm{MHz}$ bandwidth). These three electrical signals, together with a PMT (HAMAMATSU ${ }^{\circledR}$ 1P28HA) signal corresponding to the discharge light collected by this PMT using an optical fiber, were recorded using a oscilloscope (Lecroy ${ }^{\circledR} \mathrm{HRO} 66 \mathrm{Zi}, 600 \mathrm{MHz}, 12$ bits). The optical fiber was in quartz and has been placed perpendicular to the discharge and at a distance of $5 \mathrm{~cm}$ from the discharge. Due to its numerical aperture of 0.2 , the fiber collected the light emitted by the entire discharge. 

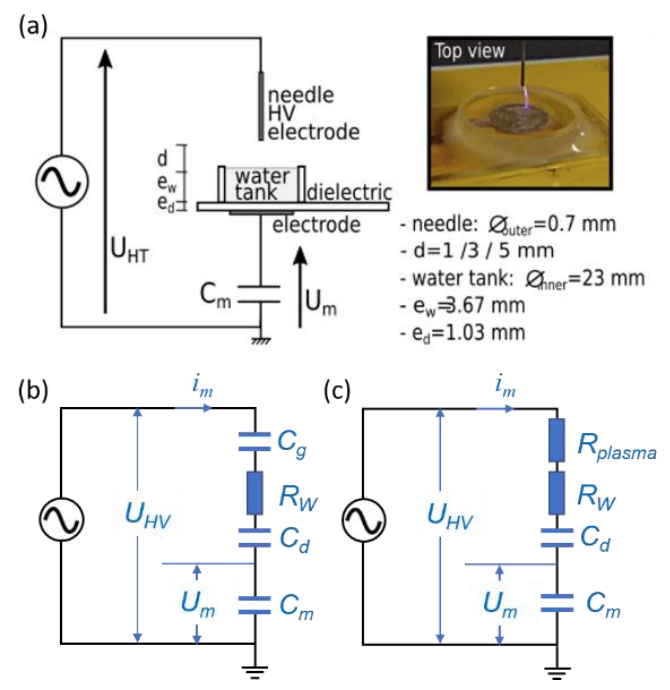

FIG. 1. (a) Scheme of the experimental setup with the main dimensions and a picture of the discharge device. (b) The equivalent circuit without discharge and (c) The equivalent circuit with discharge.

The pin-to-plane DBD device with water, named "DBD device" in this paper, has a water tank of $3.67 \mathrm{~mm}$ in height and $23 \mathrm{~mm}$ in inner diameter. Tap water, with a conductivity of about $400 \mu \mathrm{S} / \mathrm{cm}$, was used except for the experiment on the influence of the conductivity on the dissipated power. To obtain higher conductivity, $\mathrm{NaCl}$ was added to the tap water. Demineralized water was used only for the experiment with water conductivity below $400 \mu \mathrm{S} / \mathrm{cm}$. The HV electrode in stainless steel is a very thin capillary needle with outer and inner diameters of $0.7 \mathrm{~mm}$ and $0.5 \mathrm{~mm}$, respectively. The $1.03 \mathrm{~mm}$ thick dielectric is in Borosilicate glass with a relative permittivity of 4.6. The discharge was ignited in the air above the water at atmospheric pressure.

In this work, the used high voltage (HV) had sinusoidal waveform with an amplitude ( $\hat{\mathrm{U}})$ ranging from 9 to $15 \mathrm{kV}$ and a frequency (f) ranging from 0.1 to $2 \mathrm{kHz}$. Voltages below $9 \mathrm{kV}$ were not used for systematic measurements because the discharge ignition had a stochastic behavior for distance larger than $3 \mathrm{~mm}$. For each measurement, the HV has been applied for a very short duration of four cycles, typically. For instance, for the frequency of $1 \mathrm{kHz}$, the HV has been applied for $4 \mathrm{~ms}$ and the discharge lasted only about $4 \mathrm{~ms}$ for each measurement. The chosen duration was enough for the discharge to reach its "steady state" from the point of view of the dissipated power (i.e. the power measurement gave quasi-constant value from the third cycle of the HV signal). Indeed, under our experimental conditions, the mean power only needed one or two cycles to stabilize at an average value with a fluctuation of less than $5 \%$. 
This short duration was chosen in order to maintain constant experimental parameters such as temperature and conductivity of the water sample. Indeed, with the constantly applied high voltage at $1 \mathrm{kHz}$, after one minute (60000 cycles), the conductivity increased by $30 \mu \mathrm{S} / \mathrm{cm}$. Therefore, for the discharge duration of 4 cycles, the change in conductivity of about $2 \mathrm{nS} / \mathrm{cm}$ was negligible.

When the voltage is low, i.e. lower than the breakdown voltage, there is no electrical discharge; without water, the device is equivalent to two capacitances in series [13,21], known as $C_{g}$ and $C_{d}$, where $C_{g}$ is an equivalent capacitor due to the air gap, while $C_{d}$ is the equivalent capacitor due to the dielectric thickness (see FIG. 1 (b)). In the present work, with the presence of water over the dielectric, there are three components in series: a capacitor $C_{g}$ (corresponding to the air gap between the electrode and the water surface), a resistance $R_{W}$ related to water that is in the order of $10 \mathrm{k} \Omega$ for a conductivity of $10 \mu \mathrm{S} / \mathrm{cm}$, and a capacitor $C_{d}$ (corresponding to the dielectric (glass)).

As mentioned above, the water "disk" has a diameter of $23 \mathrm{~mm}$ and a height of $e_{w}=3.67 \mathrm{~mm}$, so the resistance of the water should be $R_{W}=8.8 \mathrm{k} \Omega$ for $10 \mu \mathrm{S} / \mathrm{cm}$ in conductivity if the conduction is homogeneous over the entire disk, with the assumption that the discharge completely covers the disk. This is unlikely, so the above value $(8.8 \mathrm{k} \Omega)$ is a lower limit of the equivalent resistance. With a dielectric constant of 80 for water, this configuration has an equivalent capacitance of $80 \mathrm{pF}$, hence a reactance of $2 \mathrm{M} \Omega$ with a frequency of $1 \mathrm{kHz}$. Similarly, as for the equivalent resistance, the actual value of the capacity must be lower than $80 \mathrm{pF}$, so the corresponding reactance has the value indicated $(2 \mathrm{M} \Omega)$ as a lower limit. So, the behavior of these two components in parallel was dominated by the resistance $R_{W}$ whose value was about $10 \mathrm{k} \Omega$ considering a water conductivity of about $10 \mu \mathrm{S} / \mathrm{cm}$. Therefore, the water was considered as a resistance alone.

In our case, $C_{g}$ and $C_{d}$ have values in the order of $1 \mathrm{pF}$ and $10 \mathrm{pF}$ respectively. With a frequency of $1 \mathrm{kHz}$, the reactance of $C_{d}$ is in the order of $16 \mathrm{M} \Omega$ (corresponding to the value of $\left.1 /\left(2 \pi \cdot f \cdot C_{d}\right)\right)$, well above the value of the equivalent resistance of the water, $R_{W}$. Thus the behavior of the branch of $R_{W}-C_{d}$ in series is equivalent to $C_{d}$ alone when the frequency is in the $\mathrm{kHz}$ range. Without plasma/discharge, the DBD device can therefore be considered as an 
equivalent capacitor, $C_{e}$, which is made up of $C_{g}$ and $C_{d}$ in series, i.e. water was considered as an electrode of the capacitors $C_{g}$ and $C_{d}$. With $C_{g} \ll<C_{d}$, one has $C_{e} \approx C_{g}$, since:

$$
C_{e}=\frac{C_{g} \times C_{d}}{C_{g}+C_{d}} \approx C_{g}
$$

With plasma, a resistance $R_{\text {plasma }}$ replaced $C_{g}$ for the air gap. The device is now equivalent to three components, i.e. $R_{\text {plasma- }} R_{W}-C_{d}$ in series and should be dominated by $C_{d}$ (see FIG. 1 (c)). However, the plasma was not negligible completely since electrical power was dissipated in the plasma device (i.e. if there was $C_{d}$ alone, the dissipated power should be much weak than the measured ones).

In FIG. 2 (a), three curves, the applied voltage, the charge $Q_{m}$ and the current of the discharge as a function of time are represented. The charge $Q_{m}$ is the charge accumulated in $C_{m}$, and was determined by the measurement of the voltage $U_{m}$ at the $C_{m}$ terminals. The applied $\mathrm{HV}$ of $15 \mathrm{kV}$ in amplitude lasted only four cycles. The FIG. 2 (b) is the zoom of the first positive half cycle of these three signals.
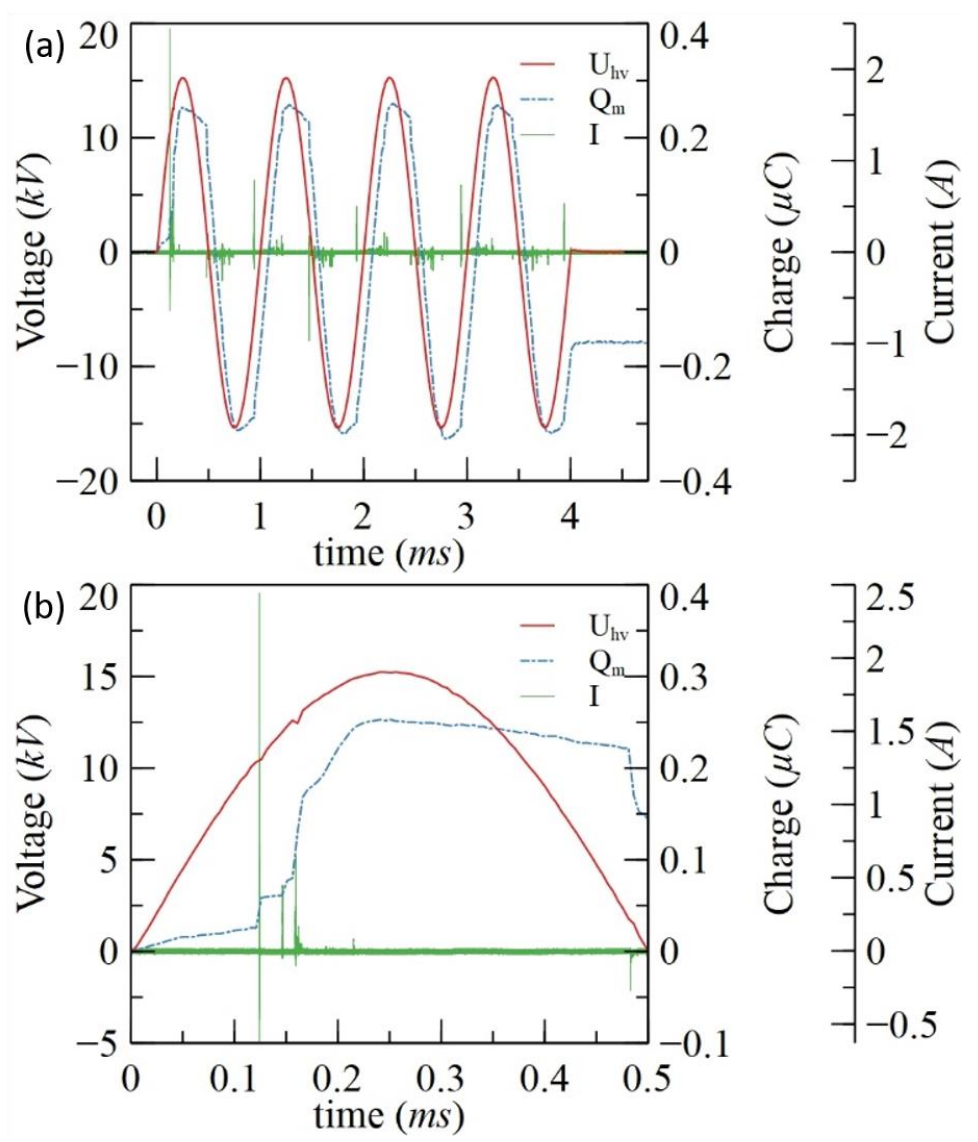
FIG. 2. (a) Applied voltage (sinusoidal waveform with a period of $1 \mathrm{~ms}$ ) of a duration of 4 cycles, discharge current (curve with fast peaks), and charge stored in $C_{m}$, called $Q_{m}$ (dashed line). $d=3.3 \mathrm{~mm}, \sigma=400 \mu \mathrm{S} / \mathrm{cm}$. (b) Zoom of the first positive half cycle of the three signals showed in the first part of this figure. The zoom showed clearly the first strong impulse of current and the induced jump of $Q_{m}$.

At the beginning, since the voltage was lower than a threshold value (about $10 \mathrm{kV}$ for a distance $d$ of $3.3 \mathrm{~mm}$ ), there was no discharge, as evidenced by the absence of current impulses. Consequently, before breakdown, there was no plasma, and the current was very low, but it was not zero, as evidenced by the slow increase in $Q_{m}$. In fact, the sinusoidal power supply had the capacitor $C_{g}\left(C_{g}\right.$ and $C_{m}$ in series according to the discussion above) as load, so a small alternating current exists, i.e. the current in the circuit $i_{m}(t)$ is not zero. That's why $Q_{m}(t)$ increased even without electrical breakdown of the air gap, since

$$
Q_{m}(t)=\int_{0}^{t} i_{m}(x) d x
$$

When the discharge was initiated, the current in the circuit, which was the discharge current creating the plasma, became much high, so $Q_{m}(t)$ increased much fast. When the voltage reached nearby its maximum value, the discharge stopped, similarly to the DBD operation described in $[12,13]$, even if these two references refer mainly to DBDs without water. During the discharge extinction, the power supply again had the capacitor $\mathrm{C}_{\mathrm{g}}$ as load, a small alternating current again existed, and thus $Q_{m}(t)$ decreased as the applied voltage decreased.

For the case of the signal shown in FIG. 2, $0.124 \mathrm{~ms}$ after the start, corresponding to a HV value of $10.3 \mathrm{kV}$, there was the first filament linking the pin electrode to the water surface, enabling the passage of a strong impulse current, as monitored by the current probe (see FIG. 2 (b)). This current pulse transported a large amount of charge, inducing a positive jump on the curve $Q_{m}(t)$. Then, $0.022 \mathrm{~ms}$ after the first filament, corresponding to a $\mathrm{HV}$ value of $12 \mathrm{kV}$, other strong impulse currents induced another jump of $Q_{m}$. Then, the discharge with current flowing from pin electrode to water, called positive discharge in this paper, continued with a more regular current until the applied voltage reached nearby its peak value $\hat{U}$ and the discharge stopped. At the discharge stop time, the positive charge in the water was maximum. With time advancement, the applied voltage decreased and the discharge restarted when the voltage amplitude reached $1.8 \mathrm{kV}$. As this discharge had a current flowing from the water to the $\mathrm{HV}$ electrode, it is called negative discharge. The discharge lasted until the time when the applied voltage reached nearby its negative peak value $-\hat{U}$ and the discharge stopped. At the discharge 
stop time, the negative charge in the water was maximum. Due to this negative charge, the next positive discharge started at a voltage value of $-5.7 \mathrm{kV}$, much lower than the one for the first discharge at the beginning, and was sustained until nearby the positive peak of the applied voltage. With time advancement, a negative discharge reappeared and the sequence repeated until the stop of the applied HV that lasted 4 cycles for all measurements reported in this paper. During preliminary tests, the a.c. high voltage was sometimes applied constantly and under this condition, a filament can be observed with the naked eye. The filament is straight near the pin electrode, then more or less curved close to the water surface.

Although this work was focused on injected power measurement, several ICCD pictures were recorded with camera gate-width of $250 \mu \mathrm{s}$, corresponding to a quarter cycle, as the frequency was $1 \mathrm{kHz}$. Three such images are shown in FIG. 3. Even though they were timeintegrated from the point of view of the typical duration of a filament in a DBD discharge, they enabled us to observe that the morphology is different depending on the discharge polarity. The image in FIG. 3(a), which was recorded during the positive cycle, shows a strongly branched corona discharge with some of the filaments reaching the water surface. The showed six filaments were not simultaneous, corresponding to the current impulses. FIG. 3(b) shows a weak corona-like discharge recorded during the negative cycle. These discharges were produced under $\hat{\mathrm{U}}=12 \mathrm{kV}$. With a higher voltage, for instance $\hat{\mathrm{U}}=15 \mathrm{kV}$, the corona-like discharge during negative cycle transformed into an intense filament as shown in FIG. 3(c).

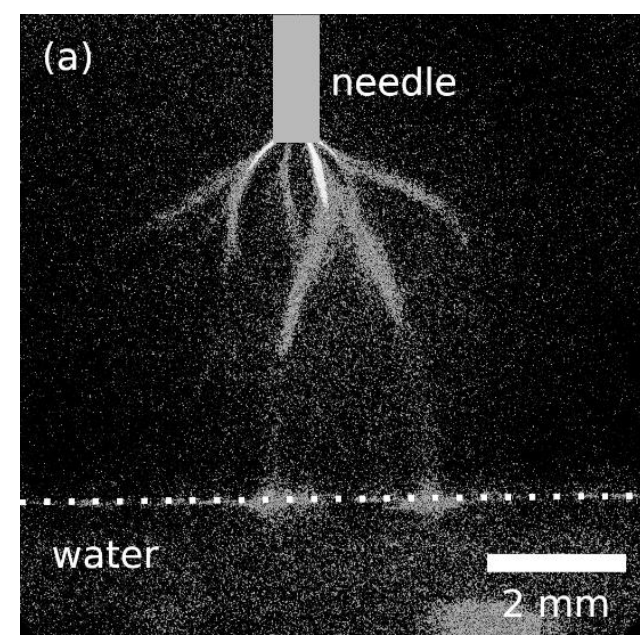



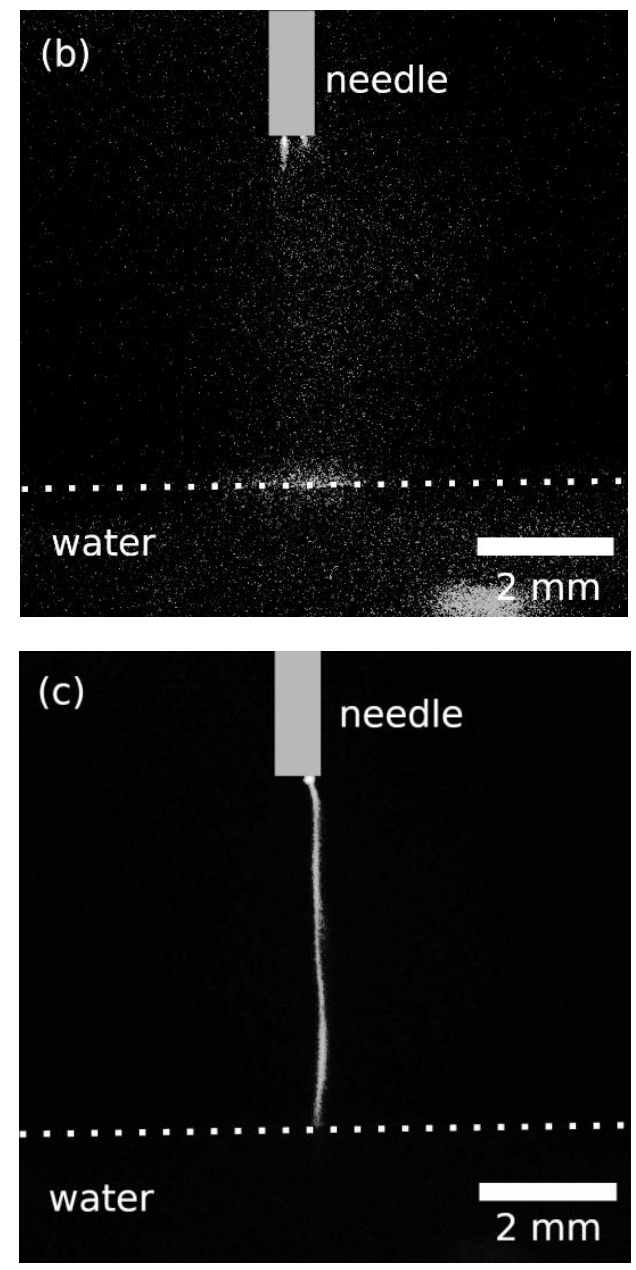

FIG. 3. Discharge images integrated over only one camera shot with an exposure time of $250 \mu$ s in the second cycle. (a) during the positive cycle, $\hat{\mathrm{U}}=12 \mathrm{kV}$, (b) during the negative cycle, $\hat{\mathrm{U}}=12 \mathrm{kV}$, (c) during the negative cycle, $\hat{\mathrm{U}}=15 \mathrm{kV}$.

FIG. 4 (a) shows a typical PMT signal as a function of time, together with the voltage and the current. As the current, the PMT signal shows the beginning of the discharge period and it confirms that the discharge stopped during about a quarter of a cycle between the positive discharge and the negative one. Except for the first positive half cycle, the light seems globally reproducible each cycle. During each discharge phase, the light decreased and the decreasing was a little faster in the negative half cycle. In the reference [19] investigating a similar configuration, the PMT signal remained not zero for a short time after the positive maximum value of the applied voltage; while, in reference [20] studying another similar configuration, the PMT signal remained not zero for a short time after the negative minimum value of the applied voltage. These two works showed that there was a dim discharge beyond the maximum 
values of the voltage. Our measurements are not accurate enough to observe the actual dim discharge.

The PMT signal for the voltage amplitude of $12 \mathrm{kV}$ is shown in FIG. 4(b) allowing the comparison to the PMT signal obtained at $15 \mathrm{kV}$, represented in FIG. 4(a). From the point of view of the emitted light, at $12 \mathrm{kV}$ peak voltage the electric discharge is less reproducible from one cycle to another, which is certainly a reflection of a lower reproducibility of the morphology of the discharge observed in the ICCD images. The signal during the positive half-cycle, for the first three cycles, comprises many pulses corresponding to the filaments observed in FIG. 3(a). During the fourth cycle, the light extends over the quarter of a positive cycle, similarly to the signal observed with $15 \mathrm{kV}$. During the negative half-cycle, the light is usually extended over the quarter of the negative cycle. This pattern of light emission corresponds well to the weak corona-type discharge at the electrode.

Li et al [20] also observed a difference in the PMT signals on the positive and negative halfcycles. Furthermore, they also reported that with an increase in applied voltage, there was a change in regime, from a corona discharge to a filamentary one. In our case, with increasing voltage from $12 \mathrm{kV}$ to $15 \mathrm{kV}$, we have obtained a similar transition for the negative half-cycle, that is to say from a corona localized close to the needle electrode to a continuous filament bridging the gap from the electrode to the liquid, over the quarter period. For the positive halfperiod, there is a transition from a pulsed filamentary discharge to a continuous filamentary discharge. 

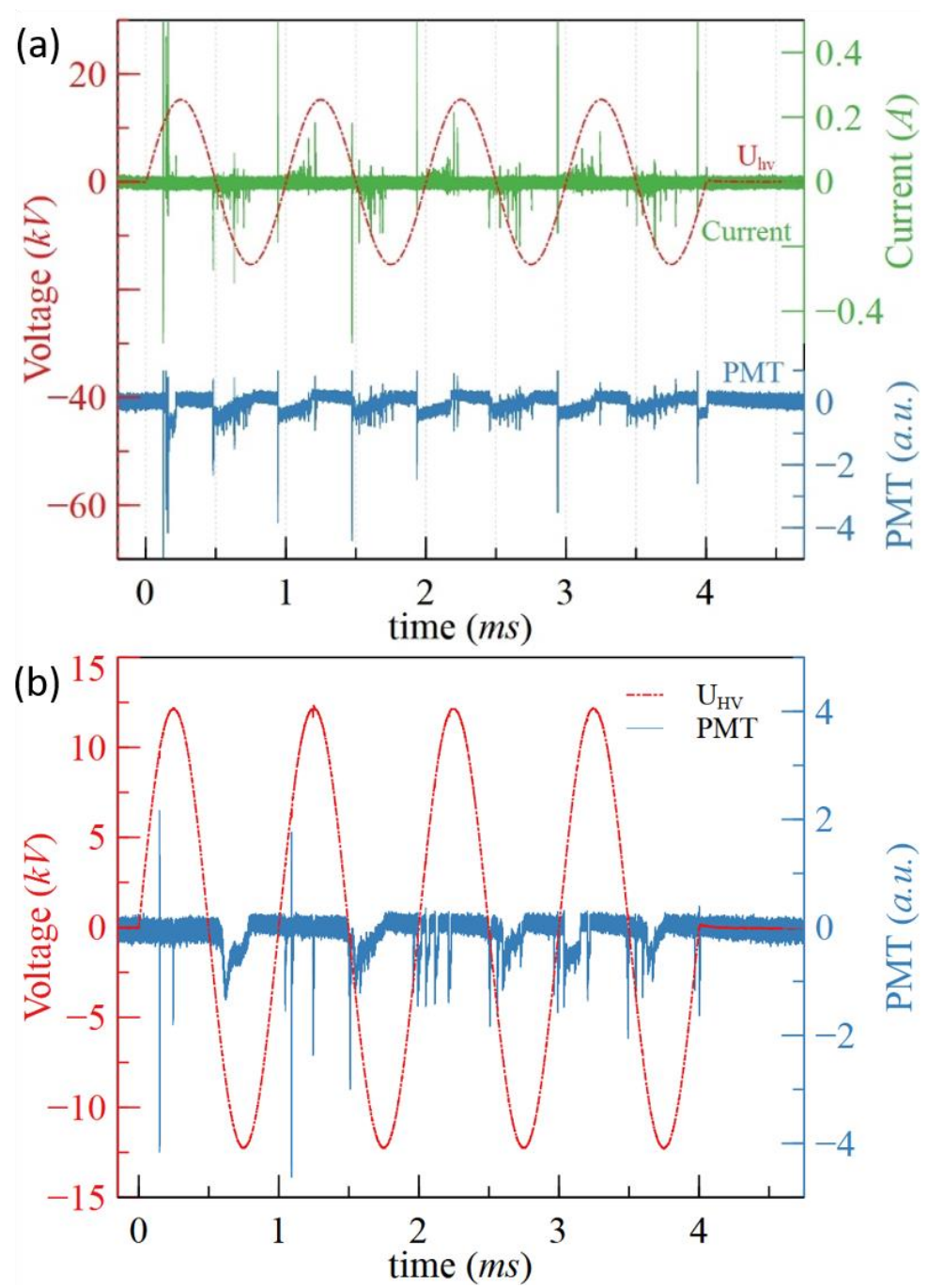

FIG. 4. (a) Applied voltage, current and PMT signal during the 4 cycles. The experimental conditions: $d=5 \mathrm{~mm}$, $\sigma=400 \mu \mathrm{S} / \mathrm{cm}, \hat{U}=15 \mathrm{kV}$ and $f=1 \mathrm{kHz}$. (b) PMT signal and voltage at $\hat{\mathrm{U}}=12 \mathrm{kV}$.

The main measured quantity in this paper was the active power provided by the power supply (PS) to the entire system including in water and in probes. The instantaneous power delivered by the PS is:

$$
p(t)=U_{H V}(t) \times i_{m}(t)
$$

where im is the current in the unique loop, so the "current monitored" by the capacitor $\mathrm{Cm}$. Thus, the mean active power, provided by the PS, also called injected power or dissipated power, is:

$$
P=\frac{1}{T} \int_{0}^{T} p(t) d t=\frac{1}{T} \int_{0}^{T} U_{H V}(t) \times i_{m}(t) d t=\frac{1}{T} \oint U_{H V}(t) d Q_{m}
$$


The integral is the net energy provided by the PS during one cycle and corresponds to the area enclosed by the Lissajous figure $U_{H V^{-}} Q_{m}[13,21]$. FIG. 5 shows an experimental Lissajous figure $U_{H V^{-}} Q_{m}$. During the positive discharge, the charge $Q_{m}$ increases with voltage and the slope should be $C_{d}[13,21]$. In our figure, the increase in $Q_{m}$ is not exactly linear and shows the beginning of an almond shape due to the expansion of the plasma [23, 24]. When this method is used to determine the energy injected by cycle, the uncertainty is related to the accuracy of the two voltage probes, that of the oscilloscope and the value of the capacitor $\mathrm{Cm}$. Under our conditions, the relative uncertainty of the dissipated power determination was estimated at $5 \%$.

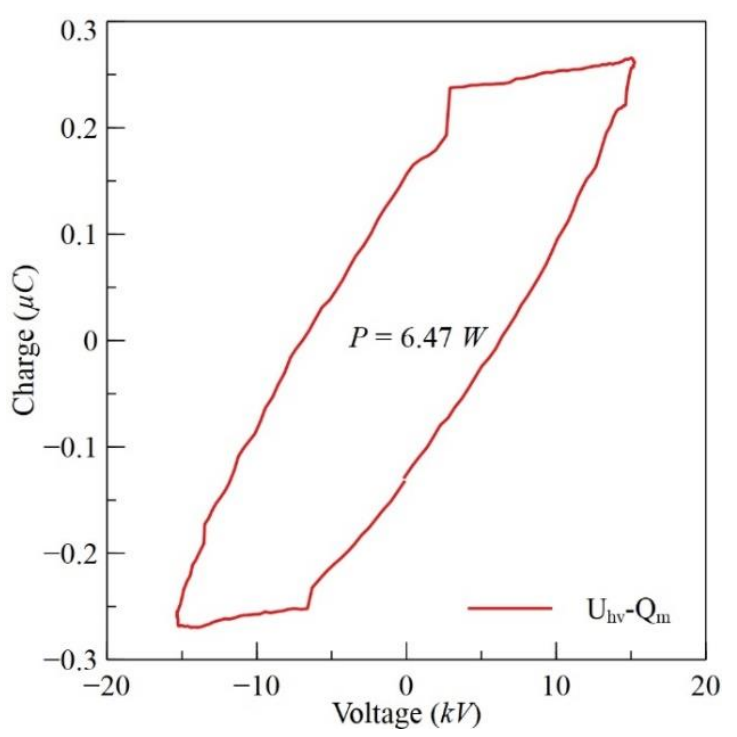

FIG. 5. Lissajous figure $U_{H V^{-}} Q_{m}$. The experimental conditions: $d=3.3 \mathrm{~mm}, \sigma=400 \mu \mathrm{S} / \mathrm{cm}, \hat{U}=15 \mathrm{kV}$ and $f=1 \mathrm{kHz}$.

The Lissajous method was used to measure the energy dissipated by cycle, over the first 100 cycles under the experimental conditions with $\mathrm{d}=5 \mathrm{~mm}, \hat{\mathrm{U}}=12 \mathrm{kV}, \mathrm{f}=1 \mathrm{kHz}$ and conductivity of $400 \mu \mathrm{S} / \mathrm{cm}$. The experimental data have been presented in FIG. 6(a). It can be seen that the energy fluctuates by less than $5 \%$ around an average value. Concretely, the average energy is $3.24 \mathrm{~mJ}$ and the standard deviation is $0.13 \mathrm{~mJ}$, which represents $4 \%$ of the average value.

FIG. 6 (b) presents the energy dissipated per cycle in each of the first four cycles at two indicated experimental conditions. Four experiments were done for each condition. It can be noted that the energy of the first cycle is much lower, indicating that the discharge in this condition required 1 or even 2 cycles to stabilize from the point of view of energy consumption 
per cycle. For this reason, energy in the first cycle was not taken into account in the results presented in section III.
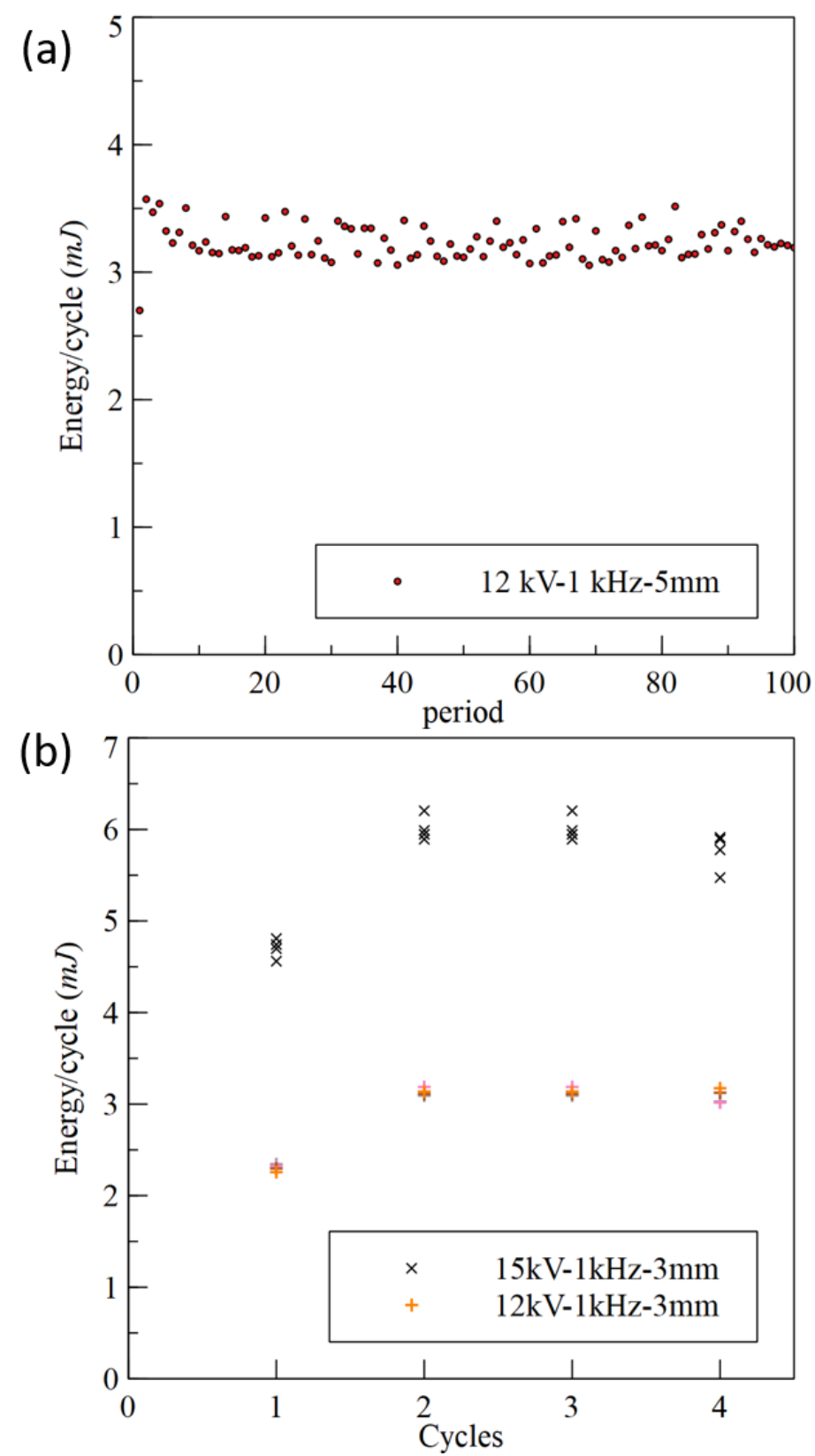

FIG. 6. (a) Energy dissipated per cycle for the first 100 cycles. The experimental conditions: $\mathrm{d}=5 \mathrm{~mm}, \sigma=400$ $\mu \mathrm{S} / \mathrm{cm}, \hat{\mathrm{U}}=12 \mathrm{kV}$ and $\mathrm{f}=1 \mathrm{kHz}$. The relative uncertainty of each individual measurement was estimated to be $5 \%$. (b) Energy dissipated per cycle for the first four cycles. The experimental conditions: $\mathrm{d}=3 \mathrm{~mm}, \sigma=400 \mu \mathrm{S} / \mathrm{cm}$, $\hat{\mathrm{U}}=12 \mathrm{kV}$ and $15 \mathrm{kV}$, and $\mathrm{f}=1 \mathrm{kHz}$.

\section{RESULTS AND DISCUSSION}


First, for a given distance of $5 \mathrm{~mm}$ between the HV electrode and the water surface, the dissipated power was measured as a function of the high voltage amplitude $\hat{U}$ for a frequency of $2 \mathrm{kHz}$. In the range of 9 to $15 \mathrm{kV}$, the power evolved linearly, as indicated by the plot in FIG.

7. The error bar for each experiment condition in this paper is the standard deviation of more than 8 experimental values. The power is approximately given by $2.01 \times(\hat{\mathrm{U}}-8.92)$ in watt with $\hat{U}$ in $\mathrm{kV}$.

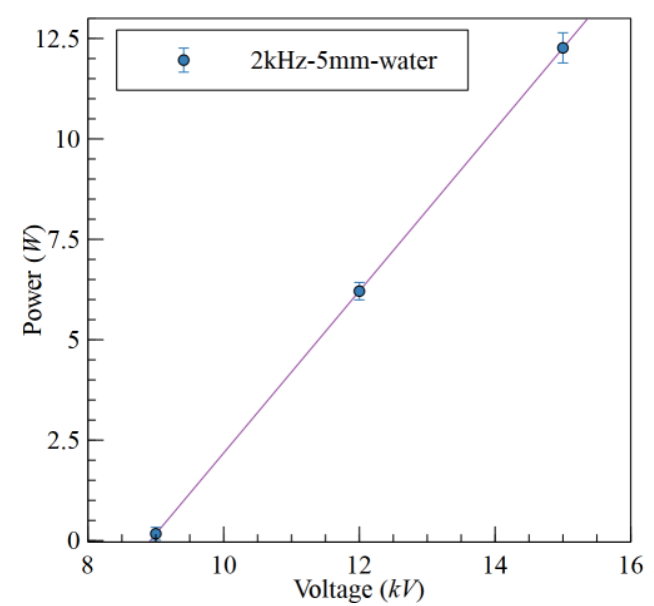

FIG. 7. Dissipated power as a function of the amplitude of the sinusoidal applied voltage. Experimental conditions: $d=5 \mathrm{~mm}, \sigma=400 \mu \mathrm{S} / \mathrm{cm}$ and $f=2 \mathrm{kHz}$.

In case of a BDB discharge without water, for the dissipated power, some authors proposed $A \times\left(\hat{\mathrm{U}}-U_{0}\right)^{2}$, where $U_{0}$ corresponds roughly to the ignition voltage of the discharge $[25,26]$. Roth and Dai [27] showed that the power according to the applied voltage $\hat{U}$ followed a law between $\hat{U}^{2}$ and $\hat{U}^{3}$, while Enloe et al. established a dependence of $\hat{U}^{7 / 2}$ [28]. As these DBDs concerned mainly the surface DBD, we performed measurements in our DBD device without water and a distance of $5 \mathrm{~mm}$ from the pin electrode to the dielectric. The experimental results were well fitted by a polynomial formula $0.028 \times(\hat{\mathrm{U}}-6.38)^{2}$ in watt with $\hat{U}$ in $\mathrm{kV}$ as shown in FIG. 8. 


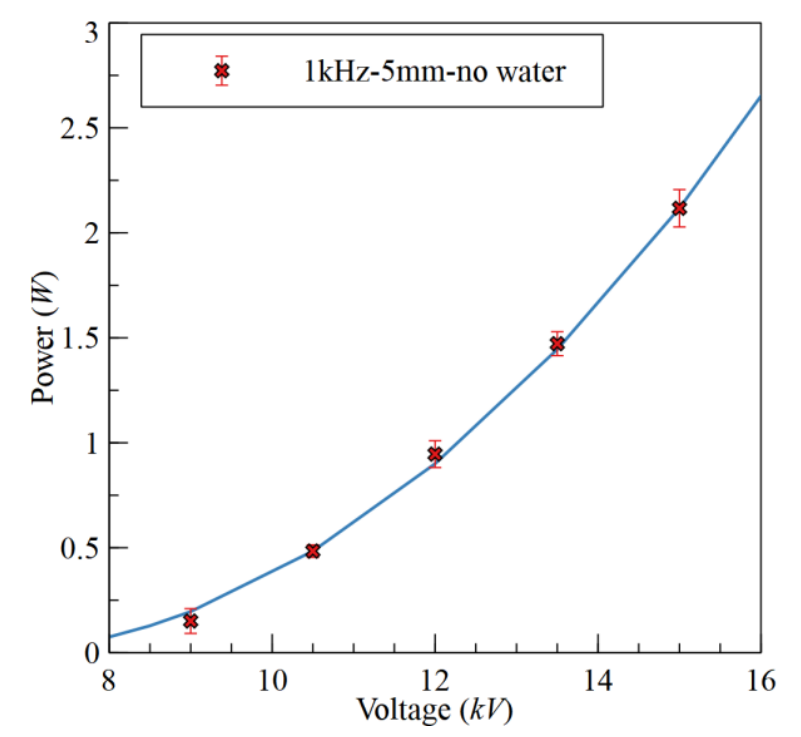

FIG. 8. Dissipated power as a function of the amplitude of the sinusoidal applied voltage without water. The experimental conditions: pin-to-dielectric distance $d=5 \mathrm{~mm}$ and $f=1 \mathrm{kHz}$.

The circle data points in FIG. 9 give the dissipated power for three distances, namely, 1, 3 and $5 \mathrm{~mm}$ from the pin electrode to the water surface. It can be seen that the power increased only $15 \%$ when the air gap increased from 1 to $5 \mathrm{~mm}$. For comparison, this experiment was done without water and the relative fluctuation was found to be slightly greater, about $20 \%$ of the maximum value. The main observation is that, for the same air gap, the injected power for the DBD over water is about three times that of the DBD without water.

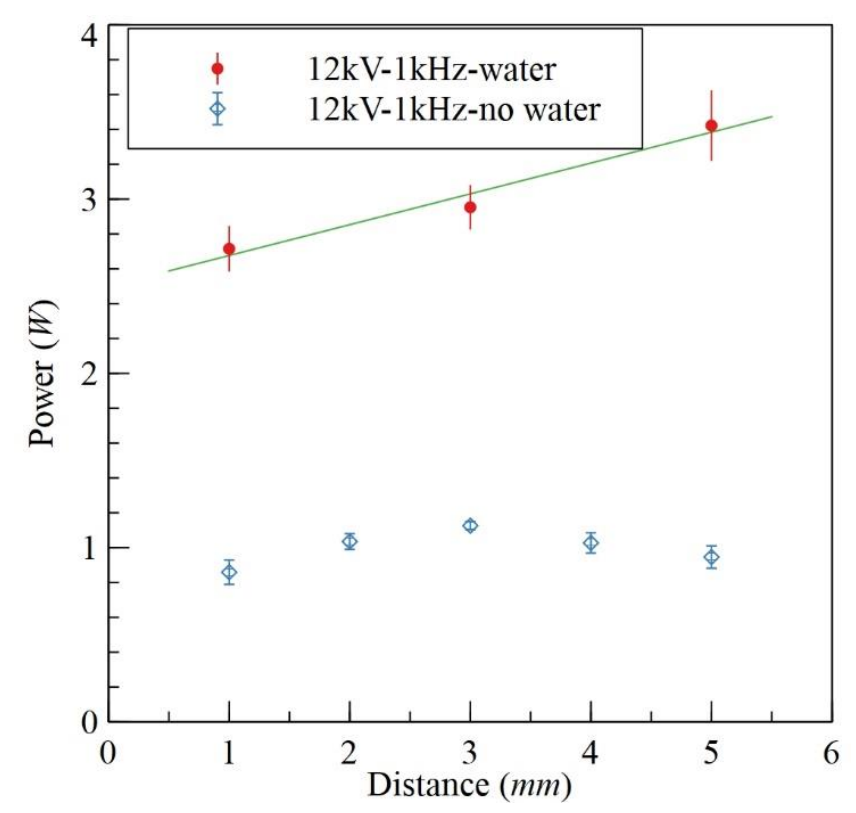


FIG. 9. Dissipated power as a function of the distance of the HV electrode from the water surface (circle symbol) or from the dielectric surface without water (diamond symbol). The experimental conditions: $\hat{U}=12 \mathrm{kV}$, $\sigma=400 \mu \mathrm{S} / \mathrm{cm}$ and $f=1 \mathrm{kHz}$.

The experiment was done for several frequencies and the injected energy during each cycle $E_{i}$ for three frequencies, namely $0.1,1$ and $2 \mathrm{kHz}$, was measured thanks to the Lissajous figure. The data were given in FIG. 10 and the quasi-constant of the energy indicated that the injected power increased linearly with the frequency over the investigated range of 0.1 to $2 \mathrm{kHz}$ since the dissipated power is given by $E_{i} \times f$. This observation is in agreement with published results, for instance by Parissi et al. [22] whose FIG. 11.4-b showed a linear increase of the discharge power with frequency, both in air and in $\mathrm{O}_{2}$.

Manlay [21] proposed the following formula to calculate the mean power dissipated by a DBD discharge:

$$
P=4 \mathrm{fC}_{\mathrm{d}} \mathrm{U}_{\text {dis }}\left(0-\frac{\mathrm{C}_{\mathrm{d}}+\mathrm{C}_{\mathrm{g}}}{\mathrm{C}_{\mathrm{d}}} \mathrm{U}_{\mathrm{dis}}\right)
$$

where $f$ is the high voltage frequency, $U_{d i s}$ is the air gap voltage during the discharge which is difficult to determine. However, this quantity is usually admitted to be constant for a given air gap. Under these conditions, for a given amplitude of high voltage, the power depends linearly on the frequency.

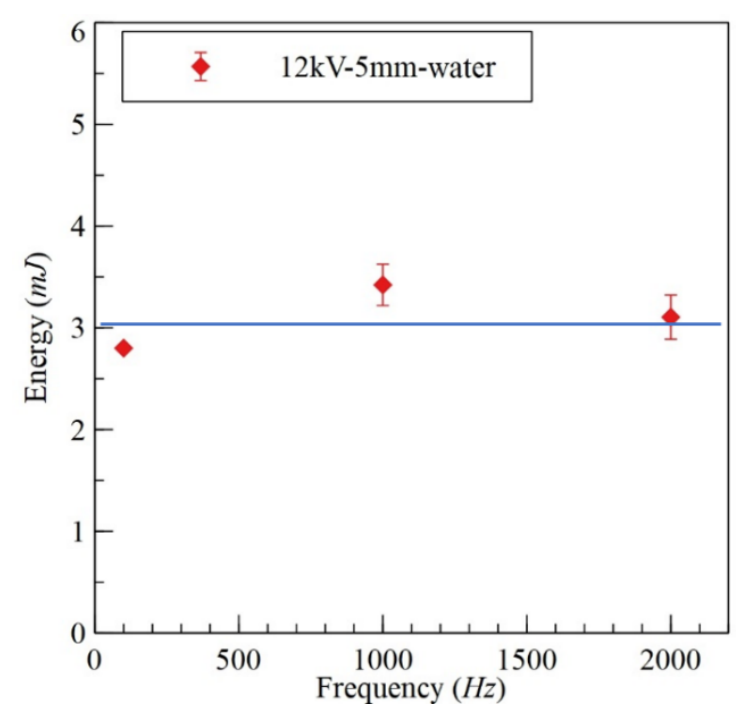

FIG. 10. Dissipated energy per cycle as a function of the frequency of the sinusoidal applied voltage. The experimental conditions: $\hat{U}=12 \mathrm{kV}, \sigma=400 \mu \mathrm{S} / \mathrm{cm}$ and $d=5 \mathrm{~mm}$. 

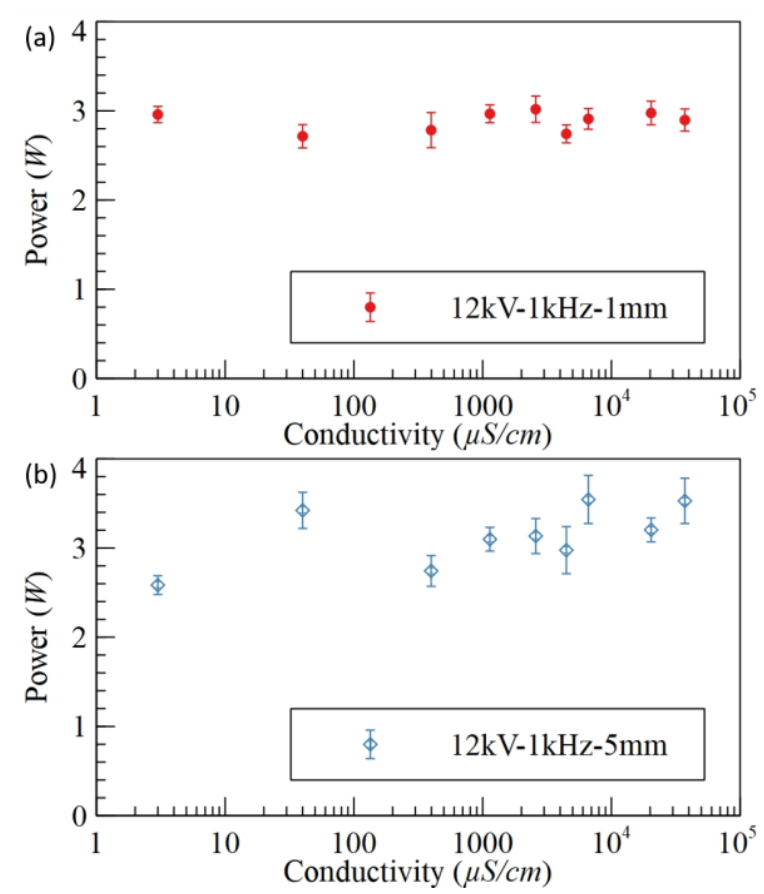

FIG. 11. Dissipated power as a function of the conductivity of the water. The experimental conditions: $\hat{U}=12 \mathrm{kV}, f=1 \mathrm{kHz}$, (a) $d=1 \mathrm{~mm}$ and (b) $d=5 \mathrm{~mm}$.

The influence of the water conductivity on the dissipated power was investigated over a wide range from 2 to $30000 \mu \mathrm{S} / \mathrm{cm}$ (FIG. 11). Results show that the dissipated power fluctuated but that the fluctuation was small with respect to the strong change in conductivity (more than four orders of magnitude). Specifically, for $d=1 \mathrm{~mm}$, the mean value was $2.89 \mathrm{~W}$ while the standard deviation was $0.15 \mathrm{~W}$; for $d=5 \mathrm{~mm}$, the mean value was $3.10 \mathrm{~W}$ while the standard deviation was $0.25 \mathrm{~W}$. According to this experiment, the dissipated power remained globally the same, while the equivalent resistance of water varied by several orders of the magnitude. This fact indicated that during the discharge, the equivalent water resistance was negligible in comparison to the reactance of the $C_{d}$ as discussed in section 2. At the higher conductivities, for a given conductivity, the measured power fluctuated more and this larger fluctuation probably indicated the lower stability of the discharge.

\section{CONCLUSIONS}

Based on this study of the basic pin-to-plane dielectric barrier discharge over water configuration, the following five observations can be made about the injected power for the 
configuration with the presence of water on the dielectric; three of these observations were compared with the behavior of a DBD without water.

1) The injected power increased linearly with the amplitude of the high voltage applied, while without water, the evolution of the injected power followed $A \times\left(\hat{\mathrm{U}}-U_{0}\right)^{2}$, with $A$ and $U_{0}$ two constants depending mainly on the geometrical parameters.

2) It fluctuated only $+/-20 \%$ while the conductivity of the water varied by over four orders of magnitude.

3) It was about three times greater than that without water with the same air gap.

4) It increased only $15 \%$ when the air gap increased from 1 to $5 \mathrm{~mm}$.

5) It was proportional to the frequency, as was also the case for the DBD without water.

We believe that these observations, especially those concerning conductivity $\sigma$ and the distance between the electrode and the surface of the water $d$, are valuable for the use of a pinto-plane DBD in water treatment.

\section{ACKNOWLEDGEMENTS}

Campus France is gratefully acknowledged for the grant PHC BRANCUSI 2019 No. 43505RC. Tian Tian would like to thank the China Scholarship Council (CSC) for scholarship in the frame of the CSC - Polytech Network PhD program (Student ID: 202009110132). Authors would also like to thank the reviewers for their relevant comments and many helpful suggestions.

\section{DATA AVAILABILITY}

The data that support the findings of this study are available from the corresponding author upon reasonable request.

\section{REFERENCES}


[1] P. Bruggeman, M J Kushner, B R Locke, J G E Gardeniers, W G Graham, D B Graves, R C H M Hofman-Caris, D Maric, J P Reid, E Ceriani, D Fernandez Rivas, J E Foster, S C Garrick, Y Gorbanev, S Hamaguchi, F Iza, H Jablonowski, E Klimova, J Kolb, F Krcma, P Lukes, Z Machala, I Marinov, D Mariotti, S Mededovic Thagard, D Minakata, E C Neyts, J Pawlat, Z Lj Petrovic, R Pflieger, S Reuter, D C Schram, S Schröter, M Shiraiwa, B Tarabová, P A Tsai, J R R Verlet, T von Woedtke, K R Wilson, K Yasui, G Zvereva, Plasma Sources Sci. Technol. $25,053002(2016)$

[2] P. Bruggeman and C. Leys, J. Phys. D: Appl. Phys. 42, 053001 (2009)

[3] P. Bruggeman, J. Van Slycken, J. Degroote, J. Vierendeels, P. Verleysen and C. Leys, IEEE Trans. Plasma Sci. 36 (4), 1138 (2008)

[4] B. R. Locke, M. Sato, P. Sunka, M. R. Hoffmann, and J.-S. Chang, Ind. Eng. Chem. Res. 45 (3), 882 (2006)

[5] P. Vanraes, A. Y. Nikiforov and C. Leys, (Plasma science and technology - Progress in physical states and chemical reactions. IntechOpen., 457 (2016)

[6] P. Vanraes and A. Bogaerts, Appl. Phys. Rev. 5, 031103 (2018)

[7] W.F.L.M. Hoeben, E.M. van Veldhuizen, W.R. Rutgers, C.A.M.G. Cramers, G.M.W. Kroesen, Plasma Sour. Sci. Technol. 9, 361 (2000)

[8] L. Wang, X. Jiang, J. Hazard. Mater. 161, 926 (2009)

[9] R. K. Singh, L. Philip, S. Ramanujam, Water Research 121, 20 (2017)

[10] S. Hu, X. Liu, Z. Xu, J. Wang, Y. Li, J. Shen, Y. Lan, C. Cheng, Plasma Sci. Technol. 21, $015501(2019)$ 
[11] M. El Shaer, M. Eldaly, G. Heikal, Y. Sharaf, H. Diab, M. Mobasher, A. Rousseau, Plasma Chem Plasma Process 40, 971 (2020)

[12] R. Brandenburg, Plasma Sources Sci. Technol. 26, 053001 (2017)

[13] U. Kogelschatz, Plasma Chemistry and Plasma Processing 23 (1), 1 (2003)

[14] Y. Baloul, O. Aubry, H. Rabat, C. Colas, B. Maunit and D. Hong, Eur. Phys. J. Appl. Phys. 79 (3), 30802, (2017)

[15] N. Korichi, O. Aubry, H. Rabat, B. Cagnon, D. Hong, Catalysts, 10 (9), 959 (2020)

[16] E. Marotta, M. Schiorlin, X. Ren, M. Rea, C. Paradisi, Plasma Process. Polym., 8, 867 2011

[17] I. Radu, R. Bartnikas and M. R. Wertheimer, J. Phys. D: Appl. Phys.36, 1284 (2003)

[18] Yu. S. Akishev, A. V. Dem'yanov, V. B. Karal'nik, A. E. Monich, and N. I. Trushkin, Plasma Phys. Reports 29, 82 (2003)

[19] P. Vanraes, A. Nikiforov, A. Bogaerts \& C. Leys, Scientific reports, 8(1): 1 (2018)

[20] X. Li, D. Niu, P. Jia, N. Zhao, N. Yuan, Plasma Sci. Technol. 13, 213 (2011)

[21] T. C. Manley, Transactions of The Electrochemical Society, 84 (1), 83 (1943)

[22] L. Parissi, E. Odic, A. Goldman, M. Goldman and J-P Borra, "Electrical Discharges for Environmental Purposes, Fundamentals and Applications, ISBN 1-56072-743-8, E.M. Van Veldhuizen (Editor), NOVA, Science Publishers, Inc. Huntington, New York. Ch. 11, 278

[23] F. Peeters and T. Butterworth, in Atmospheric Pressure Plasma - From Diagnostics to Applications, InTechOpen, Ch. 2, 23 (2019) 
[24] A. V. Pipa, R. Hink, R. Foest and R. Brandenburg, Plasma Sources Science and Technology, 29(12), 12LT01 (2020)

[25] J. Pons, E. Moreau and G. Touchard, J. Phys. D: Appl. Phys. 38, 3635 (2005)

[26] B. Dong, J. M. Bauchire, J. M. Pouvesle, P. Magnier, and D. Hong, J. Phys. D: Appl. Phys. $41,155201(2008)$

[27] J.R. Roth and X. Dai, 44th AIAA Aerospace Sciences Meeting and Exhibit. Reno, Nevada AIAA, 1203 (2006)

[28] C. L. Enloe, T. E. McLaughlin, R. D. Vandyken, K. D. Kachner, E. J. Jumper and T. C. Corke, AIAA J. $42(3) 589$ (2004) 
(a)
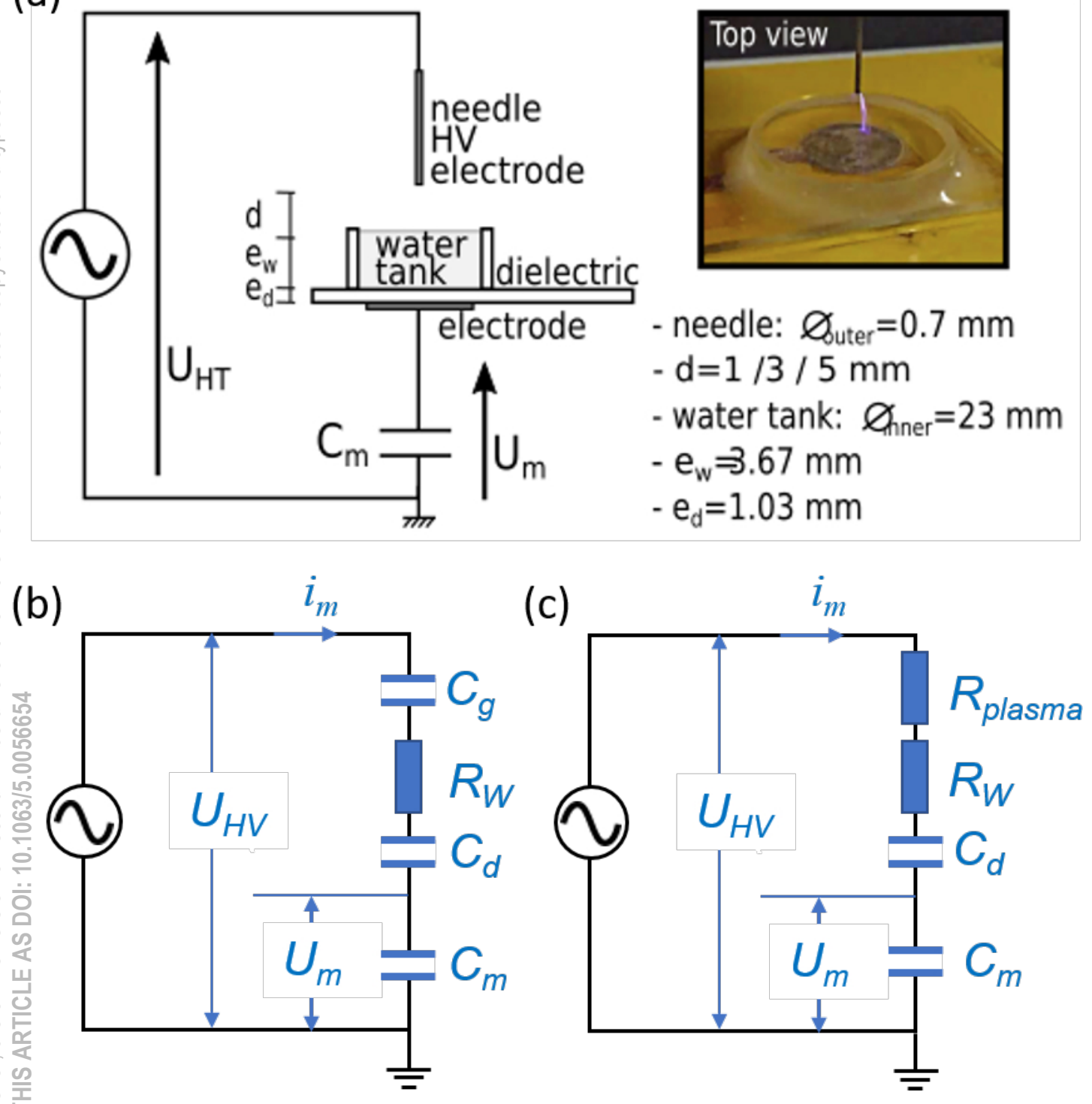
(a) 20

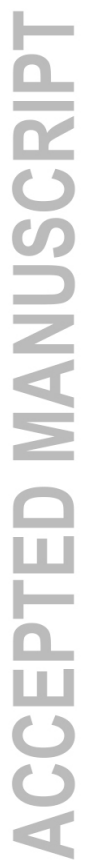
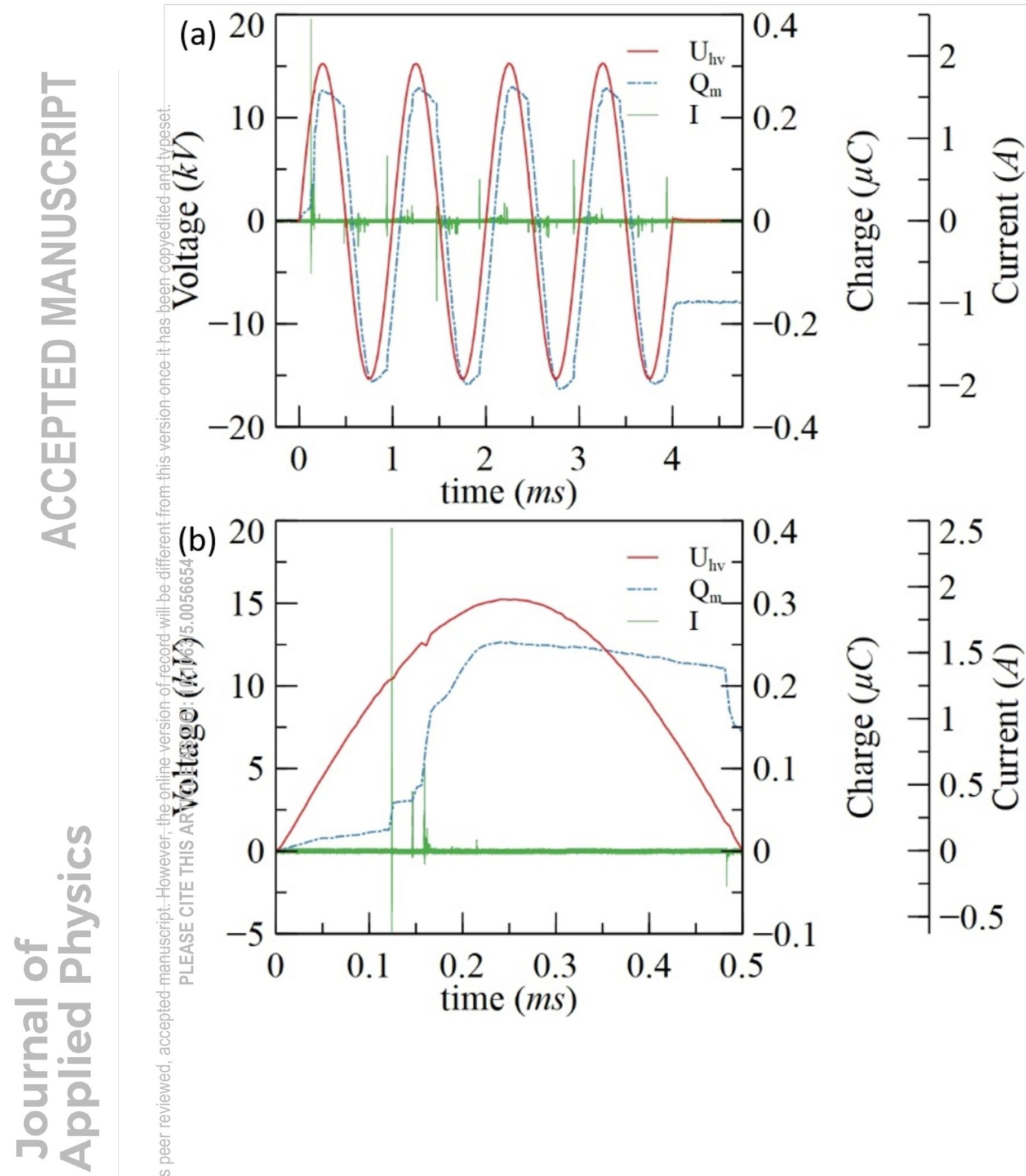

은 


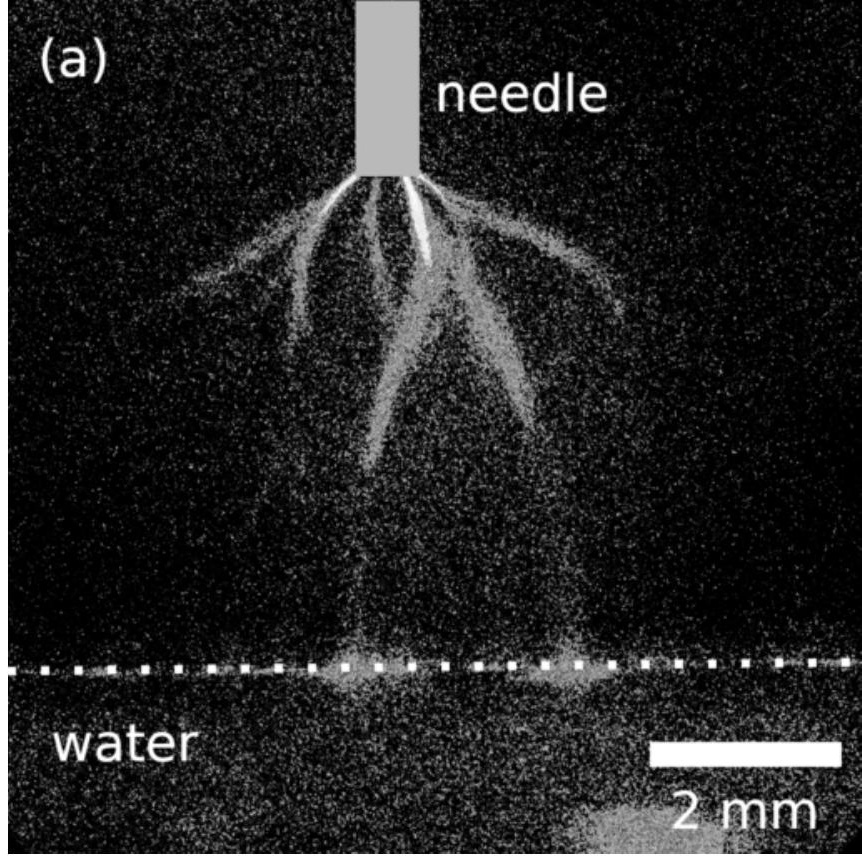

0
$U$
0
0

\begin{tabular}{ll}
0 \\
0 & 0 \\
0 & 0 \\
\hline & 0
\end{tabular}

。

兄墨旁 
(b)

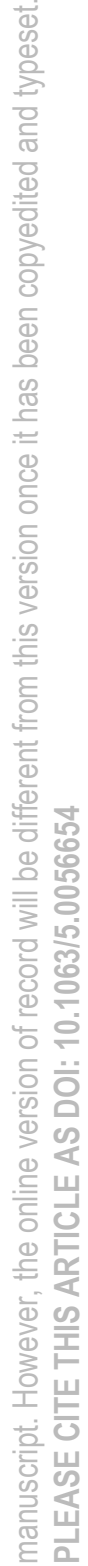
water

\section{needle}


(c)

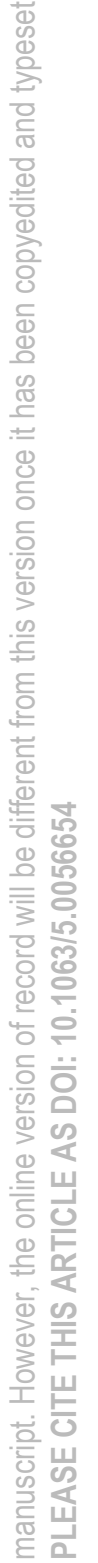

needle

water

$2 \mathrm{~mm}$

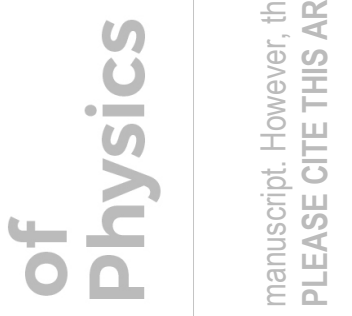

$\begin{array}{ll}0 \\ 0 & 0 \\ 0 & 0 \\ 0 & 0\end{array}$

은 

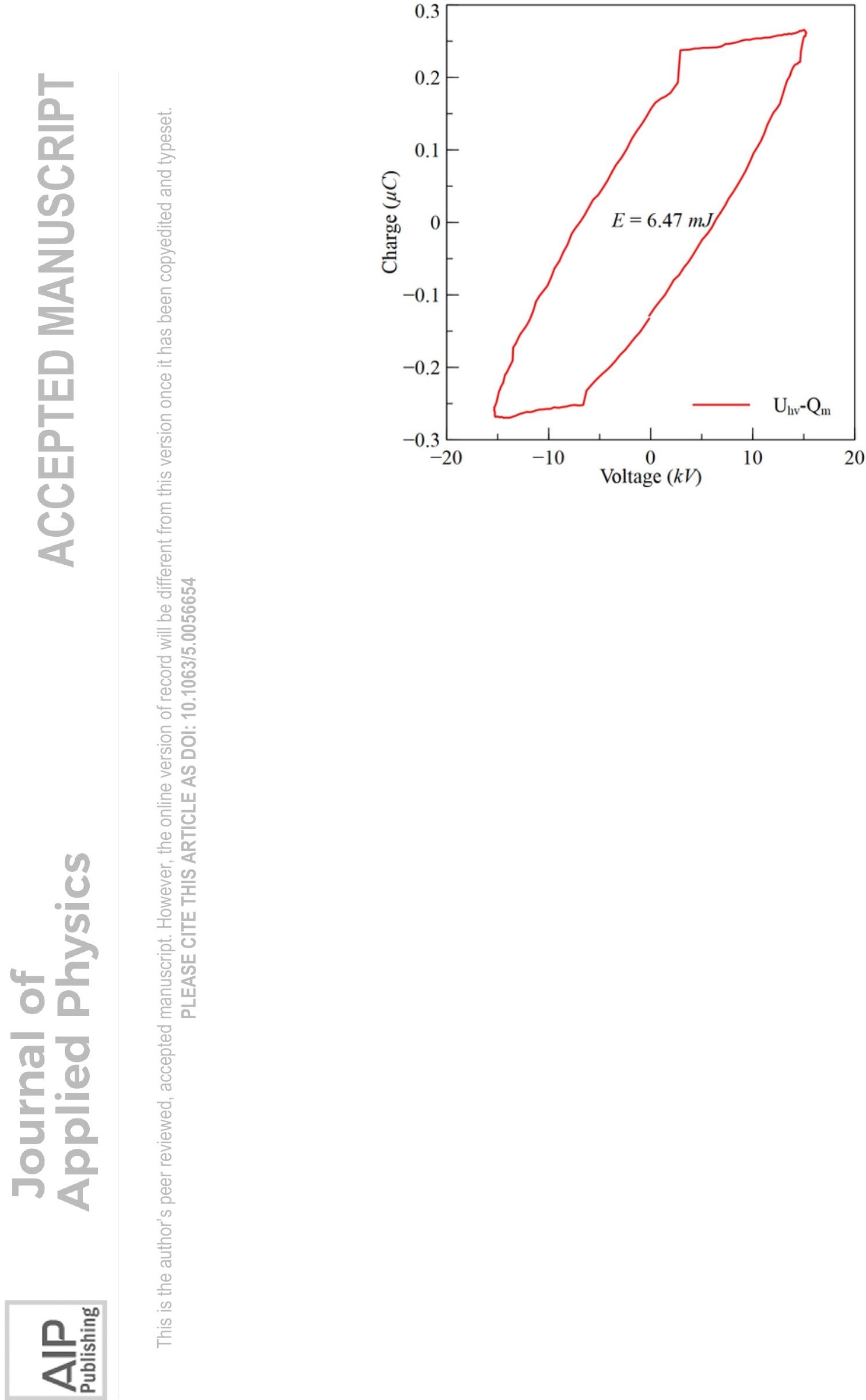

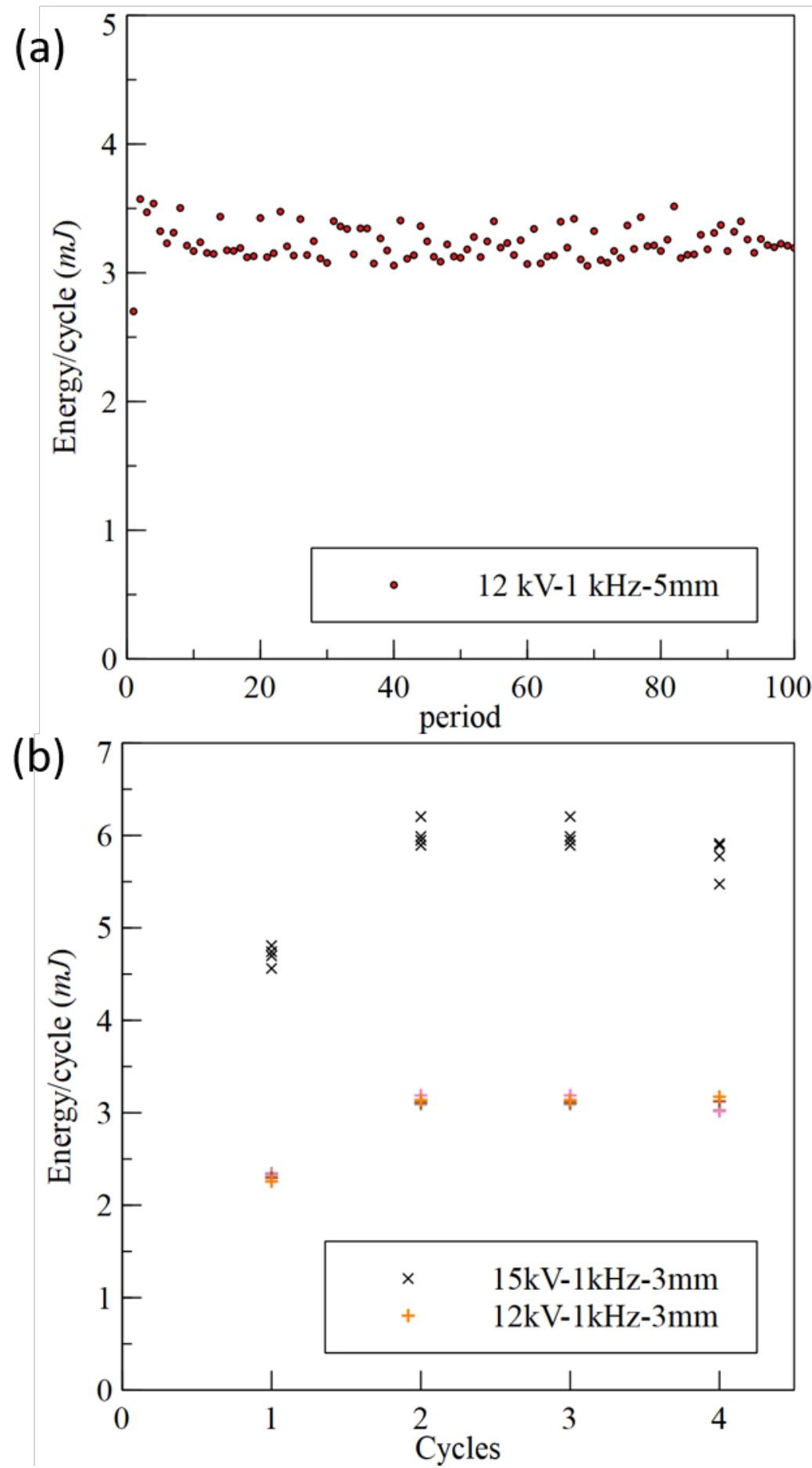

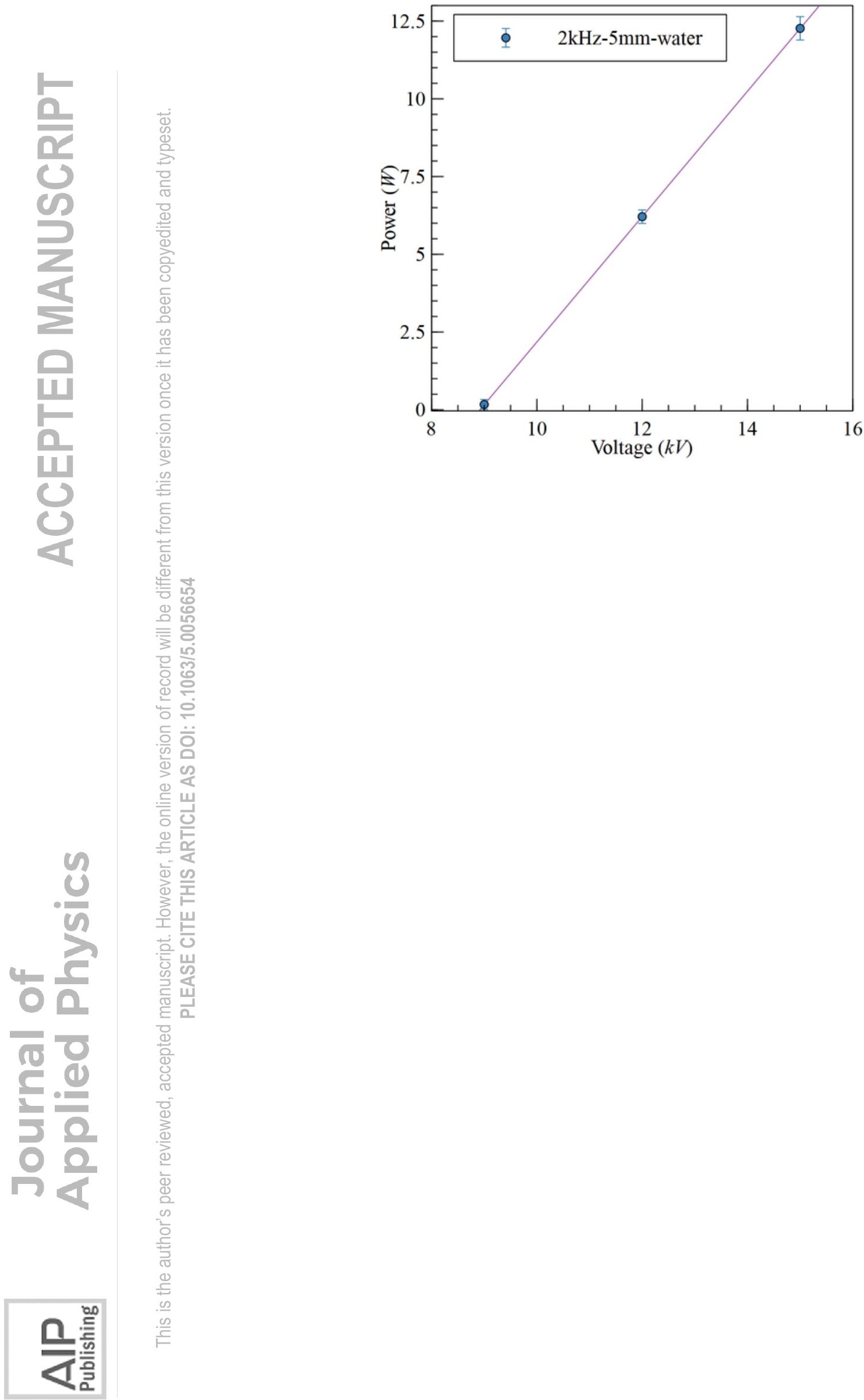

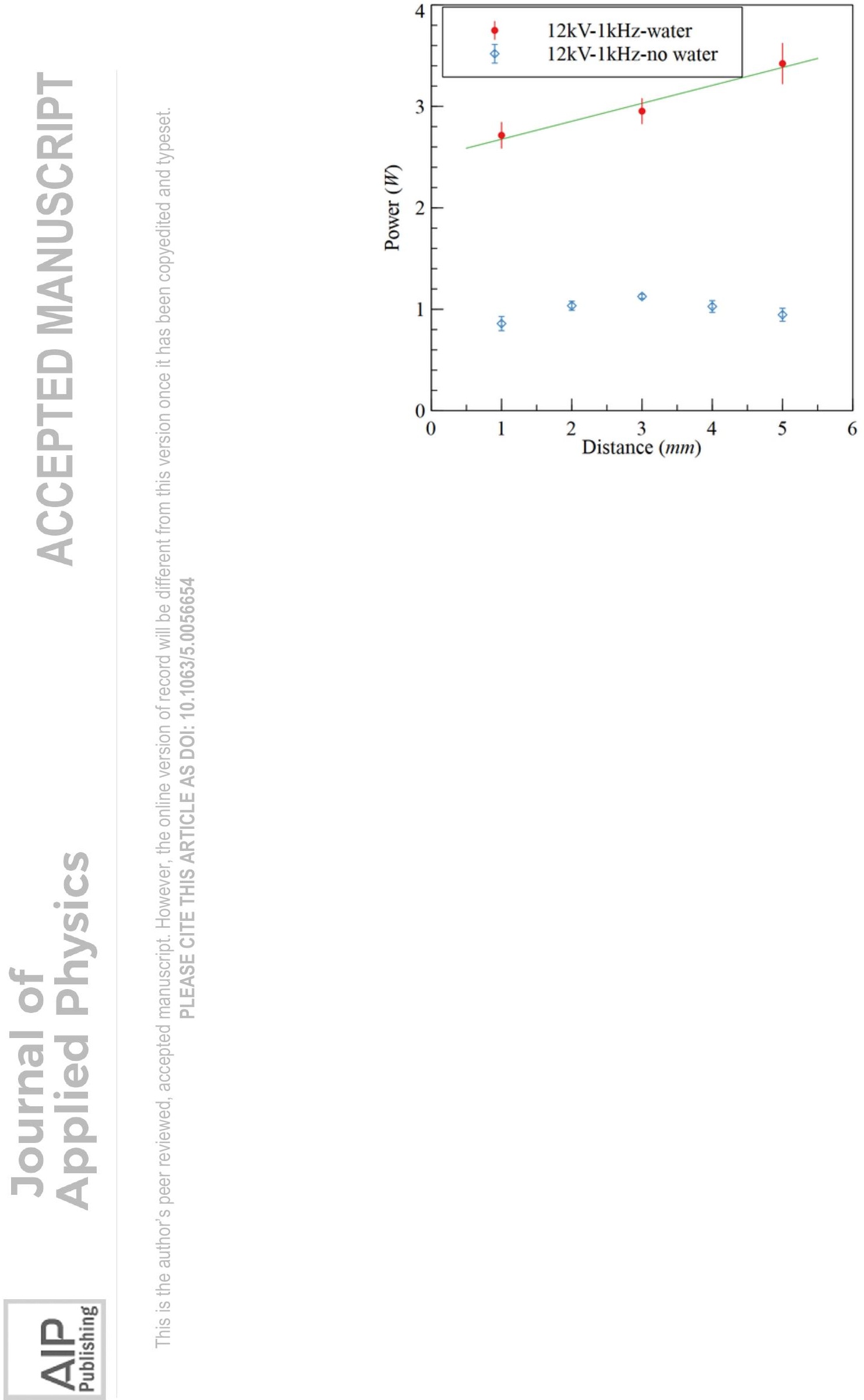

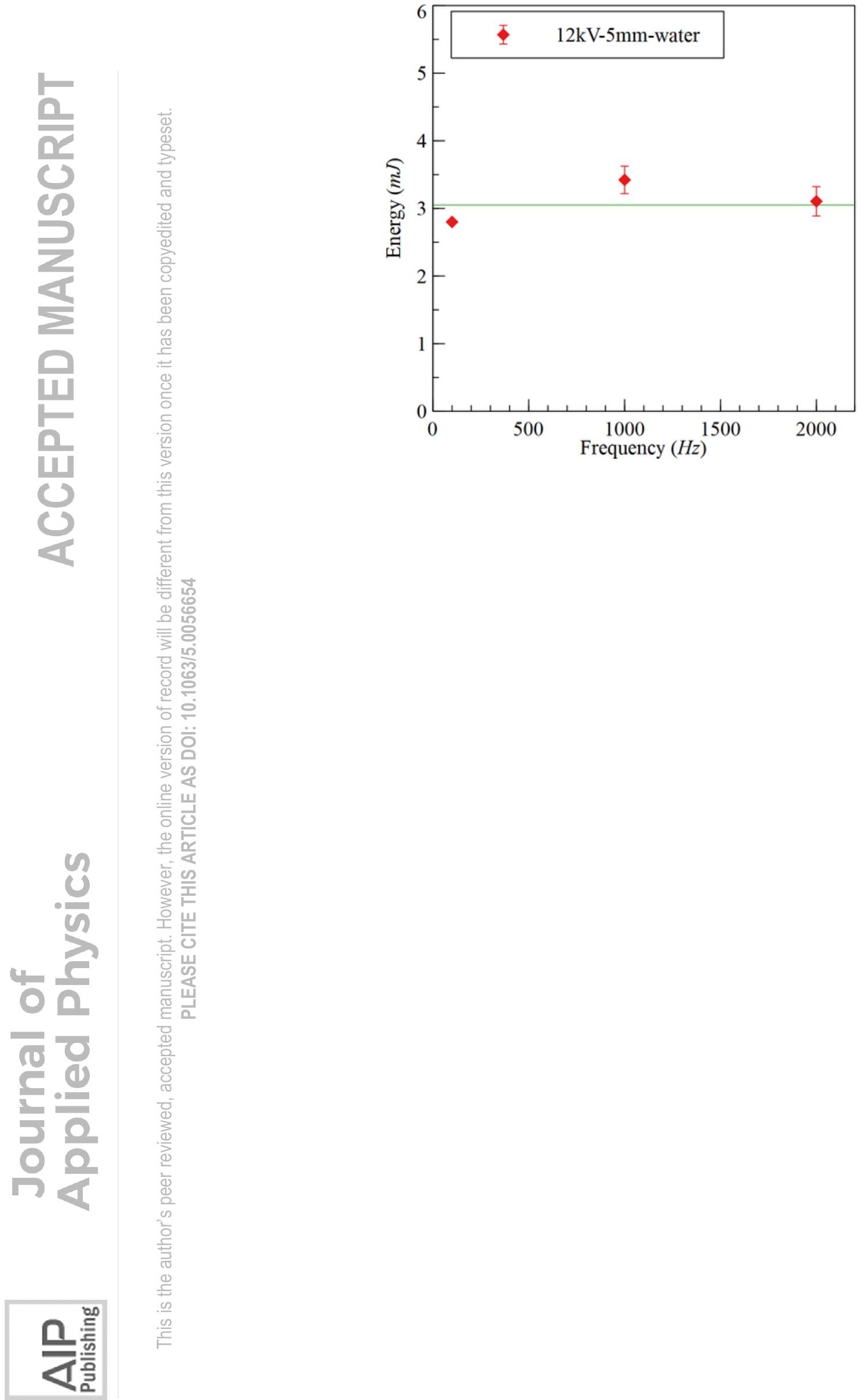
